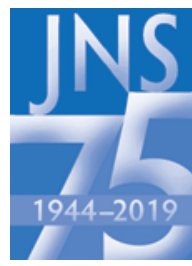

\title{
Childhood brain tumors: current management, biological insights, and future directions
}

\author{
JNSPG 75th Anniversary Invited Review Article
}

\author{
lan F. Pollack, MD, Sameer Agnihotri, PhD, and Alberto Broniscer, MD \\ Departments of Neurosurgery and Pediatrics, Children's Hospital of Pittsburgh, University of Pittsburgh School of Medicine, \\ Pittsburgh, Pennsylvania
}

\begin{abstract}
Brain tumors are the most common solid tumors in children, and, unfortunately, many subtypes continue to have a suboptimal long-term outcome. During the last several years, however, remarkable advances in our understanding of the molecular underpinnings of these tumors have occurred as a result of high-resolution genomic, epigenetic, and transcriptomic profiling, which have provided insights for improved tumor categorization and molecularly directed therapies. While tumors such as medulloblastomas have been historically grouped into standard- and high-risk categories, it is now recognized that these tumors encompass four or more molecular subsets with distinct clinical and molecular characteristics. Likewise, high-grade glioma, which for decades was considered a single high-risk entity, is now known to comprise multiple subsets of tumors that differ in terms of patient age, tumor location, and prognosis. The situation is even more complex for ependymoma, for which at least nine subsets of tumors have been described. Conversely, the majority of pilocytic astrocytomas appear to result from genetic changes that alter a single, therapeutically targetable molecular pathway. Accordingly, the present era is one in which treatment is evolving from the historical standard of radiation and conventional chemotherapy to a more nuanced approach in which these modalities are applied in a risk-adapted framework and molecularly targeted therapies are implemented to augment or, in some cases, replace conventional therapy. Herein, the authors review advances in the categorization and treatment of several of the more common pediatric brain tumors and discuss current and future directions in tumor management that hold significant promise for patients with these challenging tumors.
\end{abstract}

https://thejns.org/doi/abs/10.3171/2018.10.PEDS18377

KEYWORDS astrocytoma; brain tumor; ependymoma; genomics; medulloblastoma; targeted therapy; oncology

$\mathrm{B}$ RAIN tumors are the leading cause of childhood cancer-related deaths..$^{50}$ Although advances in surgical and adjuvant therapy have improved the survival rates of children with medulloblastoma and low-grade glioma (LGG), for which 5-year survival now exceeds $75 \%,{ }^{45,73}$ the prognosis for other tumors such as diffuse intrinsic pontine glioma (DIPG) and other midline highgrade gliomas (HGGs) remains poor., ${ }^{78}$ In addition, as survival rates for children with prognostically favorable tumors have improved, there has been growing concern that "cure" often exacts a high price in terms of late sequelae, particularly when craniospinal radiation therapy (RT) is used in young children. Accordingly, during the last 15 years, increasing emphasis has been placed on reducing the morbidity of therapy for favorable-risk tumors by applying risk-adapted treatment protocols, while attempting to improve cure rates in poor-risk tumors through the use of novel treatment regimens.

The feasibility of these goals has been dramatically augmented by the revolution in molecular biology during the last 5-10 years, which has yielded progressively more detailed insights into the genetic basis for virtually every type of childhood brain tumor. This information has not only helped to identify different subsets of tumors, now recognized by the World Health Organization (WHO) ${ }^{35}$ and warranting distinct approaches to treatment, but also

ABBREVIATIONS COG = Children's Oncology Group; DIPG = diffuse intrinsic pontine glioma; GTR = gross-total resection; HGG = high-grade glioma; LGG = lowgrade glioma; MAPK = mitogen-activated protein kinase; NF1 = neurofibromatosis type 1; NTR = near-total resection; PBTC = Pediatric Brain Tumor Consortium; PFS = progression-free survival; $\mathrm{RT}=$ radiation therapy; $\mathrm{SHH}=$ Sonic Hedgehog; SIOP = International Society of Paediatric Oncology; WHO = World Health Organization; WNT = Wingless/Integrated.

SUBMITTED October 19, 2018. ACCEPTED October 29, 2018.

INCLUDE WHEN CITING DOI: 10.3171/2018.10.PEDS18377. 
indicated molecular targets that can be exploited in therapy for certain tumors, such as pilocytic astrocytomas, dramatically changing the therapeutic landscape during the last 2-3 years. Conversely, for other tumors such as DIPGs, these insights have yielded valuable information, but translation of this knowledge to prognosis-altering therapeutics remains a work in progress, albeit one with great promise. The goal of the present review is to depict the current state of the art in molecular classification and therapeutic stratification for the most common childhood brain tumor types and to present these data in the context of recent studies and future trials.

\section{Low-Grade Glioma}

\section{Background and Historical Therapy}

Low-grade gliomas comprise several subgroups, including pilocytic, pilomyxoid, subependymal giant cell, and diffuse astrocytomas. Two cancer-predisposition syndromes, neurofibromatosis type 1 (NF1) and tuberous sclerosis complex, are associated with an increased frequency of pilocytic astrocytomas and subependymal giant cell astrocytomas, respectively. However, the majority of LGGs arise sporadically. Extensive resection is the treatment goal for superficial lesions within the cerebral and cerebellar hemispheres. After complete resection, 10-year progression-free survival (PFS) exceeds $85 \%$, versus less than $50 \%$ if there is radiologically visible residual tumor. ${ }^{73}$ After complete resection, RT or chemotherapy is rarely warranted.

Unfortunately, complete resection is not usually feasible for deep-seated, infiltrative tumors, such as those involving the hypothalamus and optic pathways, which have a worse prognosis than superficial lesions. ${ }^{1,73}$ The management of such tumors is made even more challenging by their often large size and frequent occurrence in young children, increasing the risks of adverse late effects from RT. Accordingly, conventional chemotherapy has been used during the last 2 decades to delay or avoid RT in young children. ${ }^{1,42}$ The Children's Oncology Group (COG) A9952 study randomized between two active regimens-carboplatin and vincristine versus thioguanine, procarbazine, lomustine, and vincristine-for unresectable or progressive LGGs in children without NF1. Patients with NF1-related gliomas received carboplatin and vincristine given concerns regarding alkylator-related second malignancies. Both regimens delayed tumor progression, although children without NF1 generally experienced disease progression within 5 years of therapy, highlighting the need for additional treatment options. ${ }^{1}$ Another phase III randomized trial by the International Society of Paediatric Oncology (SIOP) consortium observed that adding etoposide to carboplatin and vincristine did not improve survival. ${ }^{18} \mathrm{~A}$ variety of other conventional chemotherapy regimens, such as vinblastine, have shown activity against these tumors, but long-term disease control has remained elusive. ${ }^{33}$ Conformal RT using advanced treatment planning techniques to spare normal structures has also shown benefit in appropriately selected unresectable tumors in children older than 5 years, ${ }^{39}$ and results of the COG ACNS0221 study of this modality are expected in the near future.

\section{Molecular Insights, Current Status, and Future Directions}

While the above studies were in progress, a series of molecular analyses demonstrated that many pilocytic astrocytomas exhibit translocations or, less commonly, activating mutations of the $B R A F$ gene, which may promote tumor development (Fig. 1A). ${ }^{26,48} B R A F-K I A A$ fusions are common in cerebellar and optic pathway pilocytic tumors and lead to constitutive activation of the BRAF protein, whereas $B R A F$ mutations are more common in gangliogliomas, pleomorphic xanthoastrocytomas, and cerebral pilocytic astrocytomas (Fig. 1B) ${ }^{61}$ Tumors lacking $B R A F$ fusions or mutations often have alterations in other components of the mitogen-activated protein kinase (MAPK) signaling pathway, including NF1 mutations and $R A F$ fusions. This convergence of mutations on a single downstream pathway prompted interest in the targeted inhibition of MAPK signaling as a therapy for these tumors. Recent studies using agents that inhibit MAPK activation by blocking MEK1/2 (MAPK/ERK kinase), such as selumetinib, ${ }^{2}$ have had promising initial results. In a Pediatric Brain Tumor Consortium (PBTC) phase I study of this agent, 5 of 25 LGGs had durable partial (> 50\%) responses, and the majority had at least some tumor shrinkage. ${ }^{2}$ Based on these results, a phase II study of this agent was launched, which stratified patients by MAPK pathway mutation status (e.g., $B R A F$ translocations or mutations), histological diagnosis, and presence of NF1. Given the strong activity observed in several of these strata, new clinical trials are already incorporating MEK inhibitors alone or in combination for newly diagnosed patients.

Studies have also been conducted with vemurafenib (NCT01748149) and dabrafenib (NCT01677741), which specifically target tumors with $B R A F^{V 600 E}$ mutations. Given promising preliminary results, one ongoing phase II randomized clinical trial is already testing the activity of dabrafenib and trametinib (MEK inhibitor) against the combination of carboplatin and vincristine in children with newly diagnosed $B R A F^{V 600 E}$-mutated LGGs (NCT02684058). In addition, building on evidence that tumors in children with tuberous sclerosis have activated mTOR signaling, ${ }^{32}$ studies of mTOR inhibitors, such as everolimus, have been launched and demonstrated activity. ${ }^{29}$ Similarly, antiangiogenic agents, such as bevacizumab, have shown promising rates of disease control in preliminary studies. ${ }^{21}$ Table 1 shows a list of additional ongoing studies for patients with LGGs.

\section{Medulloblastomas}

\section{Background and Historical Therapy}

Medulloblastomas are the most common malignant brain tumors in children. ${ }^{12}$ Overall, the outcome of children older than 3 years with medulloblastoma has improved significantly in the past 40 years with the use of craniospinal RT and multi-agent chemotherapy following an extensive resection. ${ }^{44}$ Unfortunately, surviving children experience a myriad of long-term debilitating sequelae associated with therapy. ${ }^{34,47,55}$ Although a subset of patients younger than 3 years at diagnosis, specifically those with nodular/desmoplastic tumors, have a good prognosis when treated with multi-agent chemotherapy combined 


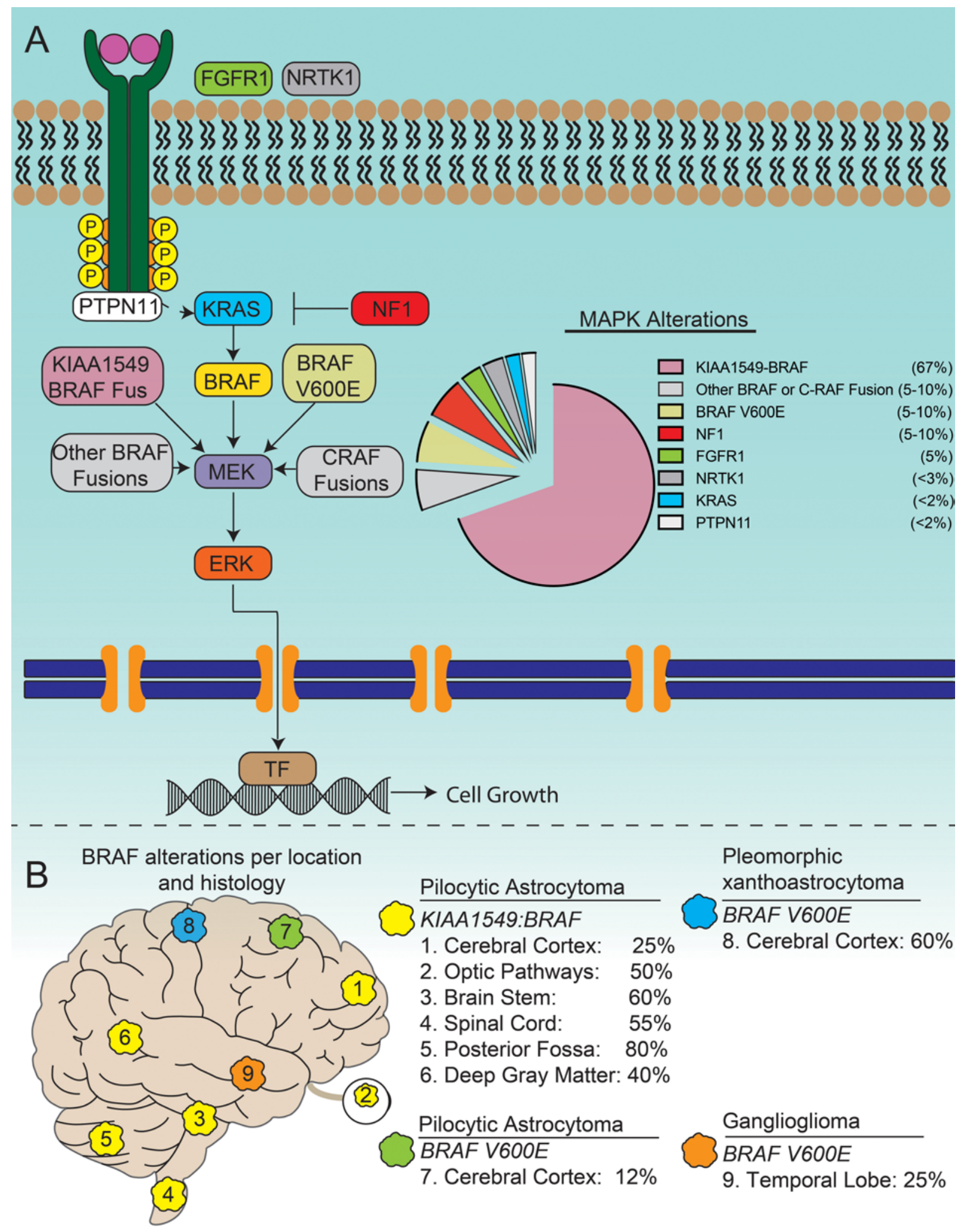

FIG. 1. A: Schematic of the frequency of MAPK pathway alterations detected by biopsy of pilocytic astrocytomas. This underestimates the frequency of NF1 mutations among children with LGGs because the tumors in patients affected by NF1 often do not undergo biopsy. Although $B R A F$ fusions (BRAF Fus) constitute the majority of alterations in pilocytic astrocytoma, $B R A F$ mutations are more commonly observed in pleomorphic xanthoastrocytomas and gangliogliomas. B: Frequency of the different $B R A F$ abnormalities as a function of tumor location and histological diagnosis. 
TABLE 1. Current experimental protocols for recurrent LGG

\begin{tabular}{|c|c|c|}
\hline Therapeutic Approach & Study Design & $\begin{array}{l}\text { Clinical Trial } \\
\text { Identification }\end{array}$ \\
\hline Use of oral vinorelbine & Phase II & NCT02197637 \\
\hline $\begin{array}{l}\text { Vinblastine vs vinblastine \& beva- } \\
\text { cizumab }\end{array}$ & $\begin{array}{l}\text { Phase II } \\
\quad \text { randomized }\end{array}$ & NCT02840409 \\
\hline $\begin{array}{l}\text { Weekly carboplatin \& vincristine vs } \\
\text { carboplatin every } 4 \text { wks }\end{array}$ & $\begin{array}{l}\text { Phase III } \\
\quad \text { randomized }\end{array}$ & NCT02455245 \\
\hline Oral everolimus (mTOR inhibitor) & Phase II & NCT01734512 \\
\hline Oral MEK162 (MEK inhibitor) & Phase II & NCT02285439 \\
\hline $\begin{array}{l}\text { Immunotherapy w/ HLA-A2-restrict- } \\
\text { ed tumor antigen peptide vaccine } \\
\text { administered w/ poly ICLC }\end{array}$ & Phase II & NCT02358187 \\
\hline $\begin{array}{l}\text { Oral TAK-580 (pan-RAF kinase } \\
\text { inhibitor) }\end{array}$ & Phase I/II & NCT03429803 \\
\hline
\end{tabular}

with intrathecal methotrexate but no $\mathrm{RT}^{60}{ }^{60}$ the remaining patients, including those with the classic or large cell/ anaplastic variants and/or metastatic disease, continue to experience poor outcomes despite the use of intensive therapies. ${ }^{60}$

Although medulloblastomas were historically subdivided into standard- and high-risk groups based on the amount of postoperative residual disease, metastatic stage, and patient age, tremendous advances in our understanding of the molecular underpinnings of these cancers have taken place during the last several years. ${ }^{12,55}$ These cancers are now subdivided in the WHO 2016 classification into four genetically defined, clinically and prognostically significant subgroups: Wingless/Integrated (WNT)-activated, Sonic Hedgehog (SHH)-activated, group 3, and group 4 (Fig. 2). ${ }^{12,55}$ Medulloblastoma subgroups can now be identified by multiple methods, including immunohistochemistry.

\begin{tabular}{|c|c|c|c|c|c|c|c|c|c|c|c|c|}
\hline Subgroup & \multicolumn{2}{|c|}{ WNT } & \multicolumn{4}{|c|}{$\mathrm{SHH}$} & \multicolumn{3}{|c|}{ Group 3} & \multicolumn{3}{|c|}{ Group 4} \\
\hline Incidence & \multicolumn{2}{|c|}{$10 \%$} & \multicolumn{4}{|c|}{$30 \%$} & \multicolumn{3}{|c|}{$25 \%$} & \multicolumn{3}{|c|}{$35 \%$} \\
\hline Subtype & WNT a & WNT $\beta$ & $\mathrm{SHH} \alpha$ & $\mathrm{SHH} \beta$ & $\mathrm{SHH} Y$ & SHH ס & Group $3 \alpha$ & $\alpha$ Group $3 \beta$ & Group 3y & Group 4a & Group $4 \beta$ & Group $4 \gamma$ \\
\hline \multicolumn{13}{|l|}{ Gender } \\
\hline \multicolumn{13}{|l|}{$\begin{array}{l}\text { Subtype } \\
\text { proportion }\end{array}$} \\
\hline Age & $3-17$ & $>10$ & $3-17$ & $0-3$ & $0-3$ & $>17$ & $0-10$ & $3-17$ & $0-10$ & $3-17$ & $3-17$ & $3-17$ \\
\hline Metastases & $9 \%$ & $21 \%$ & $20 \%$ & $33 \%$ & $9 \%$ & $9 \%$ & $43 \%$ & $20 \%$ & $40 \%$ & $40 \%$ & $40 \%$ & $40 \%$ \\
\hline $\begin{array}{l}5 \text { year } \\
\text { survival }\end{array}$ & $97 \%$ & $100 \%$ & $70 \%$ & $70 \%$ & $90 \%$ & $90 \%$ & $65 \%$ & $55 \%$ & $40 \%$ & $65 \%$ & $75 \%$ & $80 \%$ \\
\hline $\begin{array}{l}\text { Copy Number } \\
\text { Changes }\end{array}$ & 6 & & $\begin{array}{l}\text { MYCN amp, } \\
\text { GLI2 amp, } \\
\text { YAP1 amp }\end{array}$ & $\begin{array}{l}\text { PTEN } \\
\text { Loss }\end{array}$ & $\begin{array}{l}\text { Balanced } \\
\text { genome }\end{array}$ & $\begin{array}{l}\text { 10q22 } \\
11 \mathrm{q} 23.3\end{array}$ & $\begin{array}{c}7^{\star}, 8 ; 10 \\
11, ; 17 q\end{array}$ & $\left|\begin{array}{l}\text { OTX2 gain, } \\
D D X 3 \\
\text { loss }\end{array}\right|$ & MYC amp & $\begin{array}{l}M Y C N \text { amp, } \\
C D K 6 \text { amp }\end{array}$ & $\begin{array}{c}\text { SNCAIP } \\
\text { dup }\end{array}$ & CDK6 amp \\
\hline Other events & & & $\begin{array}{c}\text { TP53 } \\
\text { mutations }\end{array}$ & & & $\begin{array}{l}\text { TERT } \\
\text { promotor } \\
\text { mutations }\end{array}$ & & $\begin{array}{c}\text { High } \\
G F I 1 / 1 B \\
\text { expression }\end{array}$ & & & & \\
\hline Histology & Classic, L & CA(rare) & Desn & $\begin{array}{l}\text { oplastic, } \\
\text { Classic, }\end{array}$ & $\begin{array}{l}\text { Nodular } \\
\text { LCA }\end{array}$ & & & Classic, LCA & & & Classic, LCf & \\
\hline 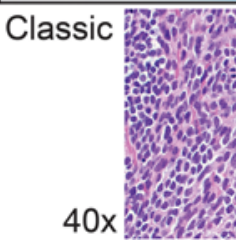 & 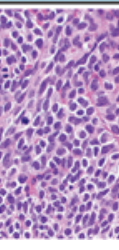 & $\begin{array}{l}\text { Desm } \\
\text { Nodu }\end{array}$ & $\begin{array}{l}\text { oplastic/ } \\
\text { lar }\end{array}$ & & & $\begin{array}{l}\text { Extens } \\
\text { nodula }\end{array}$ & $\begin{array}{l}\text { sive } \\
\text { arity }\end{array}$ & & & LCl & misis & 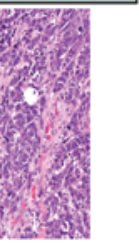 \\
\hline
\end{tabular}

FIG. 2. Schematic (upper) depicting the four WHO-recognized subgroups of medulloblastoma, as well as the additional subtypes noted more recently and their distinguishing characteristics in terms of amplifications (amp) and duplications (dup). The figure (lower) also depicts the histological diversity of medulloblastomas: WNT tumors most commonly have a classic histology, whereas $\mathrm{SHH}$ tumors have desmoplastic histology with varying degrees of nodularity. Large cell/anaplastic (LCA) histology is most commonly seen in group 3 and less commonly in group 4 tumors. 


\section{Molecular Insights, Current Status, and Future Directions}

WNT-activated medulloblastomas, which almost exclusively occur in older children and young adults, ${ }^{12}$ have unique clinical, radiological, and biological characteristics, including an origin close to the brainstem and a predisposition to hemorrhage. ${ }^{49}$ The majority of WNT-activated medulloblastomas can be readily identified by nuclear expression of beta-catenin by immunohistochemistry combined with the detection of monosomy 6 and/or CTNNBI mutations. ${ }^{12,55}$ Patients with WNT-activated medulloblastoma have an excellent prognosis when treated with standard doses of craniospinal RT and chemotherapy following surgery. ${ }^{13,16}$ Therefore, at least four multi-institutional clinical trials are currently evaluating the PFS of patients with newly diagnosed non-metastatic WNT-activated medulloblastoma treated using no (NCT02212574) or reduced doses of craniospinal RT at 18 Gy (COG ACNS1422, NCT02724579; and SIOP PNET5, NCT02066220) or 15 Gy (SJMB12, NCT01878617) and less intensive chemotherapy (COG ACNS1422 and SIOP PNET5). Eligibility criteria for all studies are strict in order to avoid the inclusion of patients with high-risk characteristics (e.g., large cell/anaplastic histology, $M Y C$ or $M Y C N$ amplification, etc.) and to include only those patients with at least two of the three positive markers described above.

SHH-activated medulloblastomas, which predominate in children younger than 3 years and in young adults, represent one of the most heterogeneous and best clinically and molecularly characterized subgroups. ${ }^{12}$ Agents targeting smoothened, a key proximal component in the SHH signaling pathway, have been approved for adults with basal cell carcinoma. ${ }^{71}$ Two smoothened inhibitors (vismodegib and sonidegib) have shown modest and temporary activity against recurrent $\mathrm{SHH}$-activated medulloblastomas, particularly in tumors harboring molecular abnormalities upstream to smoothened. ${ }^{27,57}$ Given these early results, ${ }^{27,57}$ one multi-institutional clinical trial added vismodegib as a 12-month maintenance treatment for patients with SHHactivated medulloblastoma (SJMB12, NCT01878617). Unfortunately, this study had to be amended to allow accrual of only skeletally mature patients since younger children developed significant chondropathy and growth impairment with prolonged $\mathrm{SHH}$ inhibition. ${ }^{27,56}$

The incorporation of novel agents and/or major changes in treatment strategies for patients with newly diagnosed group 3 and 4 medulloblastoma lags behind that for patients with WNT- and SHH-activated tumors. One multiinstitutional clinical trial (SJMB12, NCT01878617) is evaluating the addition of pemetrexed and gemcitabine to standard chemotherapy for patients with high-risk group 3 and 4 medulloblastoma (e.g., metastatic disease, $M Y C$ or $M Y C N$ gain or amplification, large cell/anaplastic histology) based on the promising preclinical activity of these two agents. ${ }^{43}$

Two recent clinical trials in North America (SJYC07, NCT00602667; and COG ACNS1221, NCT02017964) have shown inferior PFS of younger children with nonmetastatic nodular/desmoplastic medulloblastoma treated using combination chemotherapy without RT. ${ }^{30,58}$ In one of these trials (COG ACNS1221), ${ }^{30}$ the 1-year PFS was 66\% compared to a 5-year PFS of $90 \%$ in two consecutive Ger-
TABLE 2. Current experimental protocols for recurrent medulloblastoma

\begin{tabular}{lcc}
\hline \multicolumn{1}{c}{ Therapeutic Approach } & $\begin{array}{c}\text { Study } \\
\text { Design }\end{array}$ & $\begin{array}{c}\text { Clinical Trial } \\
\text { Identification }\end{array}$ \\
\hline $\begin{array}{l}\text { Immunotherapy w/ total tumor RNA-load- } \\
\text { ed dendritic cells \& ex vivo expanded } \\
\text { autologous lymphocyte transfer }\end{array}$ & Phase I/II & NCT01326104 \\
\hline $\begin{array}{l}\text { Local (local recurrence) or intrathecal } \\
\text { (metastatic recurrence) administration } \\
\text { of modified measles virus }\end{array}$ & Phase I & NCT02962167 \\
$\begin{array}{l}\text { Treatment w/ intravenous gemcitabine \& } \\
\text { oral ribociclib (CDK4/6 inhibitor) }\end{array}$ & Phase I & NCT03434262 \\
\hline $\begin{array}{l}\text { Treatment w/ oral ribociclib \& trametinib } \\
\text { (MEK inhibitor) }\end{array}$ & Phase I & NCT03434262 \\
\hline $\begin{array}{l}\text { Treatment w/ oral ribociclib \& sonidegib } \\
\text { (smoothened inhibitor) }\end{array}$ & Phase I & NCT03434262 \\
\hline $\begin{array}{l}\text { Treatment w/ oral LY3023414 (PI3K/ } \\
\text { mTOR inhibitor) }\end{array}$ & Phase I & NCT03213678 \\
\hline
\end{tabular}

man studies in which treatment consisted of similar intensive combination intravenous chemotherapy, but with the addition of intrathecal methotrexate. ${ }^{60,70}$

Two clinical trials, one recently completed (COG ACNS0334, NCT00336024) and one still ongoing (HeadStart4, NCT02875314), have used intensive induction chemotherapy with or without intravenous methotrexate followed by high-dose chemotherapy with stem-cell rescue to treat children younger than 3 years or younger than 10 years, respectively, with all types of medulloblastoma. The preliminary results of these studies are still not available.

Overall, although 5-year survival for older children $(\geq 5$ years of age at diagnosis) with medulloblastoma is above $75 \%$ in the United States, ${ }^{44}$ innovative therapies are badly needed for several molecularly defined subsets of patients, including those with metastatic $M Y C$-amplified group 3 or SHH-driven TP53-mutated $M Y C N$-amplified tumors or those younger than 3 years with group 3 medulloblastoma, which continue to have poor prognoses. . $^{31,55,58,63,69,75}$

The prognosis is even worse for children with recurrent medulloblastoma. ${ }^{55}$ Only a small minority of children with recurrent medulloblastoma can be cured even with the use of multimodal therapies such as high-dose chemotherapy and stem-cell rescue. ${ }^{11}$ Patients who have not undergone upfront RT, particularly younger children, can still be cured using this treatment modality with or without chemotherapy. ${ }^{72}$

Experimental (e.g., phase I and II) studies represent a common treatment alternative for such patients. Multiple innovative agents and treatment approaches are currently available for children with recurrent medulloblastoma targeting the genomic features of these tumors either pharmacologically or immunologically (Table 2).

\section{Ependymomas}

\section{Background and Historical Therapy}

Ependymomas account for approximately $6 \%$ of all childhood brain cancers. ${ }^{44}$ Approximately 190 children 
with an age $\leq 14$ years are diagnosed with ependymoma in the United States each year, less than two-thirds of whom will survive 10 years after diagnosis. ${ }^{44}$ Despite outcome improvements in affected children as compared to reports from the 1970s and 1980s, the survival of children with ependymoma has reached a plateau in the past 20 years. ${ }^{44}$

Maximal safe surgery with the intent of achieving near-total resection (NTR; maximum longest diameter of residual tumor $<5 \mathrm{~mm}$ ) or gross-total resection (GTR) followed by local fractionated RT is considered standard therapy for children with newly diagnosed non-metastatic ependymoma, except for extremely young infants. ${ }^{40}$ In a single-institution phase II study, which consisted of aggressive and frequently multiple attempts to achieve radical resection and local RT at conformally delivered agedependent doses between 54 and 59.4 Gy, the 7-year local control, PFS, and survival were $87.3 \%, 69.1 \%$, and $81 \%$, respectively. ${ }^{40}$ While $80 \%$ of the tumor progressions were equally split between local or metastatic failures, $20 \%$ of cases involved both areas. ${ }^{40}$ Extensive data have also been published about the long-term endocrinological, audiological, and neuropsychological outcomes of children treated with this approach. ${ }^{3,9,41}$

With the goal of validating this strategy in a multi-institutional setting, the COG conducted a phase II clinical trial using a similar treatment in 281 children between the ages of 1 and 20 years with non-metastatic ependymoma who underwent GTR or NTR between 2003 and 2007 (COG ACNS0121, NCT00027846). Preliminary results of this study demonstrated a 5-year PFS of $68.5 \% .^{38}$

Several clinical trials (e.g., Baby POG 1, CCG-9942) have demonstrated the activity of a combination of alkylating agents with or without cisplatin against newly diagnosed ependymomas. ${ }^{10,17}$ In the CCG-9942 study, children with non-metastatic ependymoma and residual disease following maximal safe surgery received 4 cycles of cisplatin, cyclophosphamide, and vincristine before local RT. Patients who had undergone GTR received RT only. Five-year PFS for the patients with NTR who received neoadjuvant chemotherapy was comparable to that in the patients who underwent GTR $(67 \% \pm 9 \%$ vs $58 \% \pm 9 \%$, respectively). ${ }^{17}$

\section{Molecular Insights, Current Status, and Future Directions}

Since the benefits of combining chemotherapy with local RT in patients with newly diagnosed non-metastatic ependymoma remain unproven, a few ongoing randomized clinical trials are testing this combination. A phase III randomized COG trial (ACNS0831, NCT01096368) is primarily evaluating PFS in children between 1 and 20 years of age with non-metastatic newly diagnosed ependymoma treated with local RT alone versus local RT followed by 4 cycles of adjuvant combination chemotherapy with cisplatin, cyclophosphamide, etoposide, and vincristine. All patients who have undergone NTR or GTR, except those with WHO grade II supratentorial ependymomas who have undergone microscopically complete GTR, are eligible for this randomization. Patients who have undergone subtotal resection and whose tumors have a complete response to neoadjuvant chemotherapy or those who have undergone "second look" NTR or GTR are also candidates for the randomization. Completely resected, differentiated supratentorial ependymomas are eligible for observation without RT.

In a SIOP clinical trial (EP-II, NCT02265770), patients between 1 and 21 years of age who undergo a GTR (stratum 1) are randomized either to receive a 16-week combination chemotherapy regimen with cisplatin, cyclophosphamide, etoposide, and vincristine or to undergo observation only after local RT. Patients with residual tumor following initial surgery (stratum 2) are randomized to receive neoadjuvant chemotherapy consisting of cyclophosphamide, etoposide, and vincristine with or without methotrexate. All patients with residual macroscopic tumors are eligible to receive the same post-RT 16-week chemotherapy regimen as stratum 1 patients.

Two phase II clinical trials, which have completed accrual and are in follow-up, are evaluating the outcome of patients treated with chemotherapy and local RT following maximal safe resection. In a multi-institutional study in the United States (SJYC07, NCT00602667), patients with non-metastatic ependymoma received 4 cycles of cisplatin, cyclophosphamide, intravenous methotrexate, and vincristine, followed by local RT and 6 cycles of oral cyclophosphamide and topotecan alternated with erlotinib. A European multi-institutional clinical trial (E-HIT-2000, NCT00303810) also evaluated the combination of 5 cycles of carboplatin, cyclophosphamide, etoposide, and vincristine (regimen AB4) after local hyperfractionated RT for children older than 4 years at diagnosis with WHO grade III ependymomas. Patients younger than 4 years received 5 cycles of carboplatin, cyclophosphamide, etoposide, intravenous methotrexate, and vincristine (regimen BIS4), followed by conventional fractionated local RT.

During the time that the above studies have been conducted, it has been shown that the clinical and molecular characteristics of ependymomas and the prognosis of affected patients are strongly influenced by lesion location within the central nervous system (i.e., supratentorial, posterior fossa, and spine) and patient age, reflecting the impact of distinct molecular etiologies (Fig. 3). ${ }^{46}$ Supratentorial ependymomas in children comprise two main subgroups: RELA fusion-positive (ST-RELA) ependymoma and YAPl fusion-positive (ST-YAP1) ependymoma. ${ }^{46}$ Posterior fossa ependymomas are generally referred to as group A (PF-EPN-A) and group B (PF-EPN-B). ${ }^{46}$ Three groups of spinal ependymomas have also been identified. Although therapeutic strategies targeting these subgroups have yet to be tested in clinical trials, preclinical studies are in progress in multiple laboratories to evaluate potential therapeutic vulnerabilities as well as pharmacological and immunological targets.

These novel targets may be most applicable initially in children with recurrent ependymomas. At present, reirradiation in the setting of minimal residual disease after reoperation is the only curative option for a minority of children with recurrent ependymoma. ${ }^{6}$ The outcome of patients with recurrent ependymoma who undergo a second round of RT is dependent on the pattern of recurrence and tumor molecular subtype. ${ }^{68}$ Multiple experimental clinical trials are available for patients with recurrences who are unable to receive further RT (Table 3). 


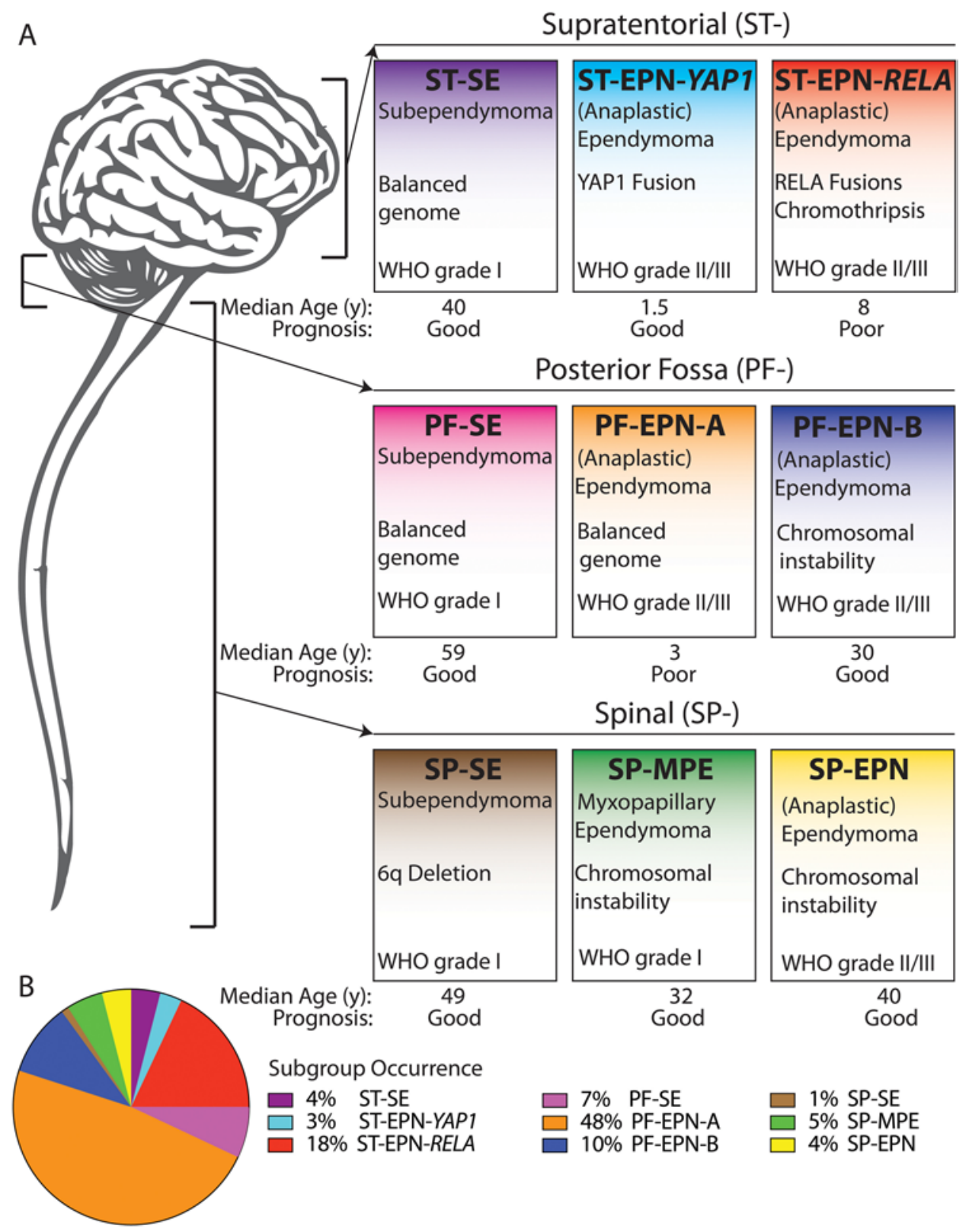

FIG. 3. A: Illustration of the nine recognized subsets of ependymomas. Only four of these subsets (ST-EPN-YAP1, ST-EPN-RELA PF-EPN-A, and PF-EPN-B) typically occur during the childhood years and thus are the focus of this paper. The subependymoma (SE) groups typically affect middle-aged or older adults, and the spinal lesions, although occasionally encountered in children, are largely seen in adults. B: Estimate of the overall frequency of the different subtypes of ependymomas.

\section{High-Grade Glioma and Diffuse Intrinsic Pontine Glioma}

\section{Background and Historical Therapy}

Malignant (high-grade) gliomas, such as anaplastic astrocytomas (WHO grade III) and glioblastomas (WHO grade IV), have a poor prognosis in children, as they do in adults. Traditionally, non-brainstem HGGs have been considered separately from DIPGs based on the fact that DIPGs, by virtue of their location within the brainstem and infiltrative growth pattern, are not amenable to extensive resection, whereas tumor debulking is often an initial goal for HGGs. For DIPGs, one of the historical limitations to overcome was that these tumors were rarely biopsied, resulting in a lack of tumor material to define molecular abnormalities and identify novel therapeutic targets. Recent efforts have focused on the acquisition of fresh or freshfrozen tumor material from autopsy or biopsy specimens for use in whole-genome analyses. ${ }^{74}$ Several groups have begun applying stereotactic biopsy to confirm the diagnosis and obtain tumor material, which has allowed DIPGs to be molecularly characterized in parallel with HGG, as noted in analyses discussed below. ${ }^{59}$

Unfortunately, progress in the management of these tu- 
TABLE 3. Current experimental protocols for recurrent ependymoma

\begin{tabular}{|c|c|c|c|}
\hline Therapeutic Approach & Study Design & $\begin{array}{l}\text { Clinical Trial } \\
\text { Identification }\end{array}$ & Limitations \\
\hline $\begin{array}{l}\text { Immunotherapy w/ HLA-A2-restricted tumor antigen peptide vaccine adminis- } \\
\text { tered w/ imiquimod }\end{array}$ & Pilot & NCT01795313 & \\
\hline $\begin{array}{l}\text { Intrathecal trastuzumab (HER2 monoclonal antibody) combined w/ subcuta- } \\
\text { neous GM-CSF }\end{array}$ & Pilot & NCT02774421 & $\begin{array}{l}\text { Limited to tumors in posterior } \\
\text { fossa }\end{array}$ \\
\hline Use of tumor-treating magnetic fields (NovoTTF-200A system) & Feasibility study & NCT03033992 & Limited to supratentorial tumors \\
\hline $\begin{array}{l}\text { Intrathecal administration of 5-azacytidine (DNA methylation inhibitor) in } \\
\text { fourth ventricle or resection cavity }\end{array}$ & Phase I & NCT02940483 & $\begin{array}{l}\text { Limited to tumors in posterior } \\
\text { fossa }\end{array}$ \\
\hline Single intratumoral administration of HSV G207 (oncolytic virus) w/ or w/o RT & Phase I & NCT02457845 & Limited to supratentorial tumors \\
\hline Combination treatment w/ intravenous carboplatin \& 5-azacytidine & Phase I & NCT03206021 & \\
\hline Treatment w/ intravenous pembrolizumab (immune checkpoint inhibitor) & Phase II & NCT02359565 & \\
\hline Treatment w/ intravenous gemcitabine \& oral ribociclib (CDK4/6 inhibitor) & Phase I & NCT03434262 & \\
\hline
\end{tabular}

GM-CSF = granulocyte-macrophage colony-stimulating factor; HSV = herpes simplex virus; TTF = tumor-treating field .

mors has been frustratingly slow. Although the addition of nitrosourea-based chemotherapy to postoperative RT was shown more than 20 years ago to increase survival rates for patients with HGG compared to rates following treatment with RT alone ${ }^{65}$ subsequent studies with different regimens have failed to further improve outcome..$^{14,36}$ Two clinical factors most consistently associated with prognosis are extent of resection and tumor histology, with grade IV lesions having worse outcomes than grade III tumors and with lesions not amenable to extensive resection having a dismal prognosis. ${ }^{14,51}$ Levels of expression of methylguanine-DNA-methyltransferase, which confers resistance to alkylating chemotherapy, have also been adversely associated with outcome in some studies. ${ }^{8,52}$

Recent trials have examined the activity of chemotherapy administered during and after RT. One COG study (ACNS0126) incorporated daily temozolomide during RT followed by adjuvant treatment cycles thereafter, ${ }^{8}$ patterned after an adult trial showing benefits to this approach. ${ }^{66}$ Unfortunately, survival was not improved compared with prior regimens. A subsequent study (COG ACNS0423) combined lomustine with temozolomide ${ }^{24}$ and noted a modest outcome benefit compared to that with temozolomide alone, although survival rates remained disappointing. The follow-up COG trial (ACNS0822), which compared the use of vorinostat or bevacizumab plus RT with the use of temozolomide plus RT followed by bevacizumab and temozolomide after RT, was equally discouraging, showing no survival advantage in the experimental arms compared to the temozolomide arm, although significant differences in outcome were noted as a function of tumor molecular features. ${ }^{23}$ More recently, the multinational randomized HERBY trial (NCT01390948) evaluated the addition of bevacizumab to RT plus temozolomide for children with newly diagnosed HGG. Unfortunately, no PFS or survival benefit for the addition of bevacizumab was observed. ${ }^{20}$

Therapeutic results have been even more discouraging in children with DIPG, with 1-year PFS rates below $20 \%$. RT is the only modality with any proven benefit, producing transient clinical and radiographic improvements. Cooperative group studies have examined escalating the ra- diation dose to 7800 cGy using hyperfractionated delivery and have noted no improvement in outcome. ${ }^{15}$ Studies of pre- and post-RT chemotherapy have been equally disappointing. ${ }^{25}$ More recent studies have attempted to enhance the activity of RT by concurrently administering chemotherapy, radiosensitizing agents, or growth factor inhibitors, but results have been uniformly discouraging. $5,7,22,54$

\section{Molecular Insights, Current Status, and Future Directions}

In recent years, it has become increasingly clear that HGGs and DIPGs in children differ on a molecular basis from HGGs in adults, and many of the molecularly targeted strategies that have been employed based on adult data have little applicability in the pediatric context. Moreover, distinct subgroups of pediatric HGG and DIPG have been distinguished based on patterns of recurring mutations and epigenetic features, which associate with biological and clinical characteristics (Fig. 4). ${ }^{37,62}$ One landmark observation was the detection of novel mutations in histones H3F3A (positions K27 and G34) and HISTIH3B (position K27). ${ }^{62}$ It was also recognized that a subset of tumors, particularly from older children, have mutations in the $I D H 1$ or $I D H 2$ genes ${ }^{53}$ whereas another subset has frequent $B R A F^{V 600 \mathrm{E}}$ mutations, similar to pleomorphic xanthoastrocytomas. ${ }^{28,67}$ Genome-wide methylation profiling suggested the existence of six epigenetically distinct subgroups of glioblastoma that include pediatric patients. ${ }^{67}$ The K27 subgroup is characterized by a midline location, typified by DIPGs and thalamic HGGs, and a predilection for affecting young children, whereas the $G 34, I D H$, and $B R A F$ subgroups most commonly arise in the cerebral hemispheres of older children, along with a subset of tumors (RTK-I) that exhibit amplification of the PDGFRA gene and a subset of so-called mesenchymal tumors. ${ }^{67}$ Retrospective cohort analysis has reported that the $K 27$ subgroup has a particularly poor long-term survival rate, whereas $I D H$ and $B R A F$ tumors have a comparatively favorable outcome; G34, mesenchymal, and RTK tumors have an intermediate, but still poor, outcome. ${ }^{23,28,67} \mathrm{~A}$ recent integrated genomic analysis of 1000 pediatric HGGs and DIPGs ${ }^{37}$ has added texture to the above classification, 


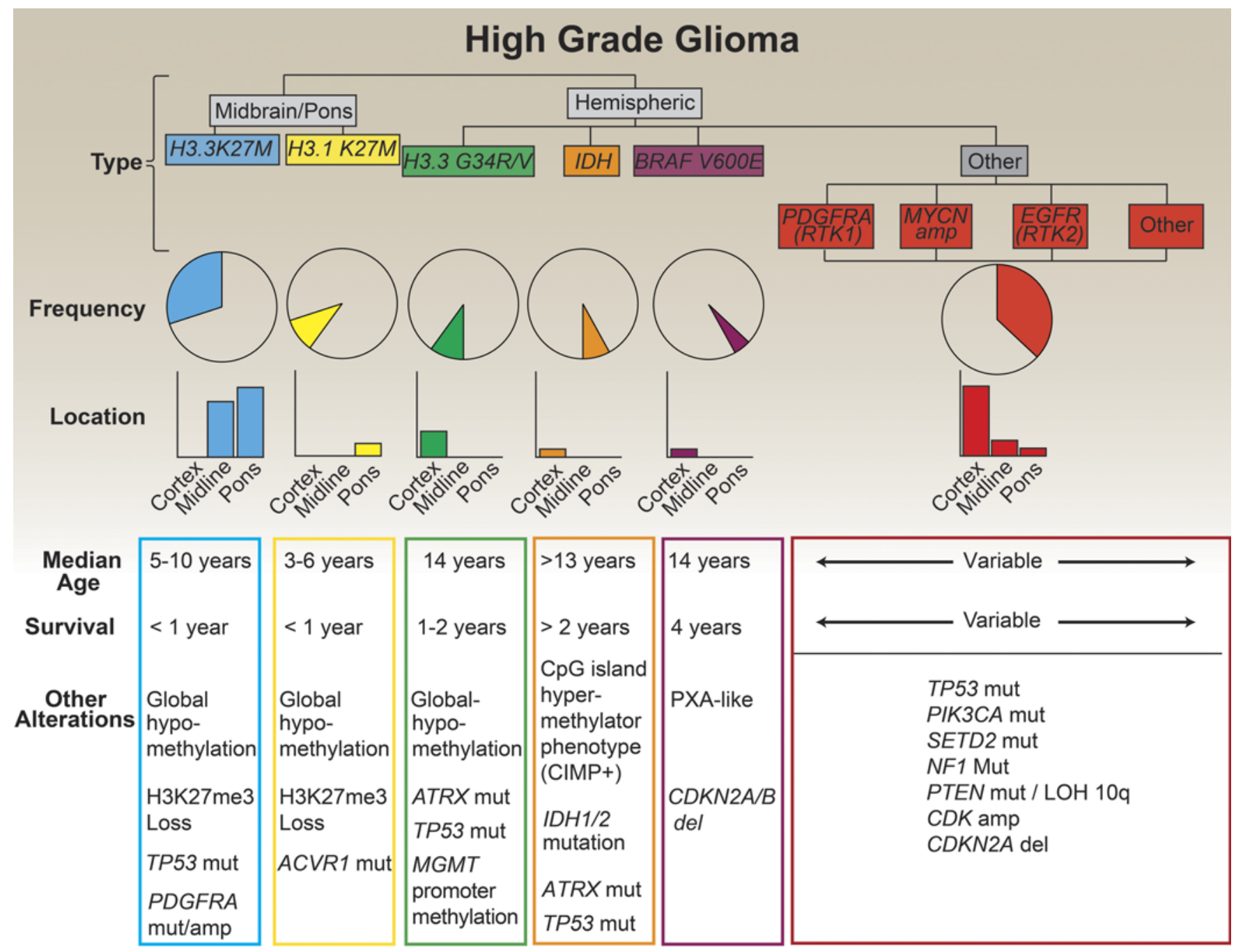

FIG. 4. Schematic illustrating the multiple subgroups of HGGs that differ based on lesion location, age at onset, and prognosis. In addition to the subgroup-defining alterations, such as BRAFV600E and histone K27M mutations, tumors commonly harbor associated mutations (mut), amplifications (amp), deletions (del), and loss of heterozygosity (LOH) in a host of other genes.

calling attention to the existence of recurring genomic anomalies within the above subgroups, which may further refine subgroup classifications. Taken together, these data highlight the genomic and prognostic diversity among these tumors, provide insights for therapeutic stratification of patients into risk groups, and suggest molecular targets for therapy.

In this context, the $K 27 M$ mutation has been targeted through the use of histone deacetylase (HDAC) inhibitors in DIPGs because of their high incidence of $K 27$ mutations. At present, the PBTC is conducting an ongoing study of panobinostat, an HDAC inhibitor that has shown efficacy in DIPG preclinical models. ${ }^{19} \mathrm{COG}$ studies of $B R A F^{V 600 E}$ and MAPK inhibition with dabrafenib and trametinib are also under development for the subset of HGGs with $B R A F$ mutations. For the subsets of tumors lacking $I D H$, $K 27$, or $B R A F$ mutations, a protocol is under development using ABT888, a poly (ADP-ribose) (PARP) inhibitor, as a radiosensitizer. In addition to the above studies, trials of novel therapeutic strategies are in progress (Table 4). The
Pacific Pediatric Neuro-Oncology Consortium is testing a peptide-based immunotherapy for patients with $K 27-\mathrm{mu}-$ tated tumors, based on encouraging preclinical data. ${ }^{6} \mathrm{~A}$ PBTC study of convection-enhanced delivery of a radioimmunoconjugate is under development based on encouraging pilot data by Souweidane et al., ${ }^{64}$ and the PBTC is also conducting studies of immune checkpoint inhibition, which holds particular promise in gliomas with a hypermutated phenotype secondary to constitutional mismatchrepair deficiency or Lynch syndrome (NCT02359565). ${ }^{4}$

\section{Conclusions}

Advances in neuroimaging, surgical technology, conformal RT delivery, and conventional chemotherapy have improved outcomes for children with several types of brain tumors. Recently, the improvement in these modalities has been complemented by advances in the molecular characterization of virtually every type of childhood brain tumor. This has formed the basis for risk-adapted treatment strati- 
TABLE 4. Current experimental protocols for HGG and DIPG

\begin{tabular}{|c|c|c|c|}
\hline Therapeutic Approach & Study Design & $\begin{array}{l}\text { Clinical Trial } \\
\text { Identification }\end{array}$ & Limitations \\
\hline Intratumoral administration of DNX-2401 (oncolytic adenovirus) & Phase I & NCT03178032 & DIPG only \\
\hline Heat shock protein peptide complex-96 (HSPPC-96) vaccine & Phase I & NCT02722512 & HGG only \\
\hline $\begin{array}{l}\text { Intracavitary \& intraventricular administration of IL13R } \alpha \text {-specific chimeric antigen receptor } \\
\text { T cells }\end{array}$ & Phase I & NCT02208362 & HGG only \\
\hline Convection-enhanced delivery of oncolytic poliovirus immunotherapy & Phase I & NCT03043391 & Recurrent HGG only \\
\hline $\begin{array}{l}\text { Convection-enhanced delivery of panobinostat (histone deacetylase inhibitor) nanoparticle } \\
\text { formulation }\end{array}$ & Phase I/II & NCT03566199 & DIPG only \\
\hline Treatment w/ oral ribociclib (CDK4/6 inhibitor) \& everolimus (mTOR inhibitor) & Phase I & NCT03355794 & DIPG \& HGG \\
\hline Treatment w/ oral PTC596 (BMI-1 inhibitor) during irradiation & Phase I & NCT03605550 & DIPG \& HGG \\
\hline $\begin{array}{l}\text { R1: erlotinib (EGFR inhibitor) vs dasatinib (PDGFRA inhibitor); R2: everolimus vs dasatinib; } \\
\text { R3: erlotinib vs everolimus vs dasatinib; dasatinib only }\end{array}$ & $\begin{array}{l}\text { Phase } \| \\
\quad \text { randomized }\end{array}$ & NCT02233049 & DIPG only \\
\hline $\begin{array}{l}\text { Treatment w/ oral vorinostat (histone deacetylase inhibitor) \& intravenous temsirolimus } \\
\text { (mTOR inhibitor) }\end{array}$ & Phase I & NCT02420613 & DIPG only \\
\hline Treatment w/ ONC201 (DRD2 inhibitor) alone or during RT & Phase I & NCT03416530 & DIPG \& HGG \\
\hline Treatment w/ oral abemaciclib during \& after RT & Phase I & NCT02644460 & DIPG only \\
\hline MRI-guided laser heat ablation followed by intravenous doxorubicin & Pilot & NCT02372409 & HGG only \\
\hline
\end{tabular}

BMI-1 = B cell-specific Moloney murine leukemia virus integration site 1; EGFR = epidermal growth factor receptor; PDGFRA = platelet-derived growth factor receptor A.

fication and revealed new classes of molecularly targeted therapeutic agents. Such insights are already beginning to influence the spectrum of first-line treatment options for LGGs; however, progress has been slower for other tumor types, for which the drug development field has not kept pace with the elucidation of new molecular targets. This situation will likely resolve itself in the coming years as new agents are developed, although one challenge that will remain is the molecular heterogeneity of most high-grade tumors as well as their tendency to develop resistance to initially effective therapies. Whereas an LGG is likely to have prolonged sensitivity to MAPK inhibitor therapy, an SHH-activated medulloblastoma may rapidly develop mutations that render it resistant to a promising inhibitor. For these high-grade tumors, it is unlikely that we will find a single magic bullet; rather, we will need to apply an arsenal of agents and strategies in order to achieve meaningful improvements in disease control.

\section{Acknowledgments}

Dr. Pollack was supported in part by NIH grant no. 1R01CA187219.

\section{References}

1. Ater JL, Zhou T, Holmes E, Mazewski CM, Booth TN, Freyer DR, et al: Randomized study of two chemotherapy regimens for treatment of low-grade glioma in young children: a report from the Children's Oncology Group. J Clin Oncol 30:2641-2647, 2012

2. Banerjee A, Jakacki RI, Onar-Thomas A, Wu S, Nicolaides T, Young Poussaint T, et al: A phase I trial of the MEK inhibitor selumetinib (AZD6244) in pediatric patients with recurrent or refractory low-grade glioma: a Pediatric Brain Tumor Consortium (PBTC) study. Neuro Oncol 19:1135-1144, 2017

3. Bass JK, Hua CH, Huang J, Onar-Thomas A, Ness KK, Jones $\mathrm{S}$, et al: Hearing loss in patients who received cranial radia- tion therapy for childhood cancer. J Clin Oncol 34:12481255,2016

4. Bouffet E, Larouche V, Campbell BB, Merico D, de Borja $\mathrm{R}$, Aronson M, et al: Immune checkpoint inhibition for hypermutant glioblastoma multiforme resulting from germline biallelic mismatch repair deficiency. J Clin Oncol 34:22062211, 2016

5. Bradley KA, Pollack IF, Reid JM, Adamson PC, Ames MM, Vezina G, et al: Motexafin gadolinium and involved field radiation therapy for intrinsic pontine glioma of childhood: a Children's Oncology Group phase I study. Neuro Oncol 10:752-758, 2008

6. Chheda ZS, Kohanbash G, Okada K, Jahan N, Sidney J, Pecoraro M, et al: Novel and shared neoantigen derived from histone 3 variant H3.3K27M mutation for glioma T cell therapy. J Exp Med 215:141-157, 2018

7. Cohen KJ, Heideman RL, Zhou T, Holmes EJ, Lavey RS, Bouffet E, et al: Temozolomide in the treatment of children with newly diagnosed diffuse intrinsic pontine gliomas: a report from the Children's Oncology Group. Neuro Oncol 13:410-416, 2011

8. Cohen KJ, Pollack IF, Zhou T, Buxton A, Holmes EJ, Burger PC, et al: Temozolomide in the treatment of high-grade gliomas in children: a report from the Children's Oncology Group. Neuro Oncol 13:317-323, 2011

9. Conklin HM, Li C, Xiong X, Ogg RJ, Merchant TE: Predicting change in academic abilities after conformal radiation therapy for localized ependymoma. J Clin Oncol 26:39653970, 2008

10. Duffner PK, Horowitz ME, Krischer JP, Friedman HS, Burger PC, Cohen ME, et al: Postoperative chemotherapy and delayed radiation in children less than three years of age with malignant brain tumors. N Engl J Med 328:1725-1731, 1993

11. Dunkel IJ, Gardner SL, Garvin JH Jr, Goldman S, Shi W, Finlay JL: High-dose carboplatin, thiotepa, and etoposide with autologous stem cell rescue for patients with previously irradiated recurrent medulloblastoma. Neuro Oncol 12:297303, 2010

12. Ellison DW, Eberhart CG, Pietsch T, Pfister S: Medulloblastoma, in Louis DN, Ohgaki H, Wiestler OD, et al (eds): 
WHO Classification of Tumours of the Central Nervous System, revised ed 4. Lyon: IARC, 2016, pp 184-200

13. Ellison DW, Onilude OE, Lindsey JC, Lusher ME, Weston $\mathrm{CL}$, Taylor RE, et al: $\beta$-Catenin status predicts a favorable outcome in childhood medulloblastoma: the United Kingdom Children's Cancer Study Group Brain Tumour Committee. J Clin Oncol 23:7951-7957, 2005

14. Finlay JL, Boyett JM, Yates AJ, Wisoff JH, Milstein JM, Geyer JR, et al: Randomized phase III trial in childhood high-grade astrocy toma comparing vincristine, lomustine, and prednisone with the eight-drugs-in-1-day regimen. J Clin Oncol 13:112-123, 1995

15. Freeman CR, Krischer JP, Sanford RA, Cohen ME, Burger PC, del Carpio R, et al: Final results of a study of escalating doses of hyperfractionated radiotherapy in brain stem tumors in children: a Pediatric Oncology Group study. Int J Radiat Oncol Biol Phys 27:197-206, 1993

16. Gajjar A, Chintagumpala M, Ashley D, Kellie S, Kun LE, Merchant TE, et al: Risk-adapted craniospinal radiotherapy followed by high-dose chemotherapy and stem-cell rescue in children with newly diagnosed medulloblastoma (St Jude Medulloblastoma-96): long-term results from a prospective, multicentre trial. Lancet Oncol 7:813-820, 2006 (Erratum in Lancet Oncol 7:797, 2006)

17. Garvin JH Jr, Selch MT, Holmes E, Berger MS, Finlay JL, Flannery A, et al: Phase II study of pre-irradiation chemotherapy for childhood intracranial ependymoma. Children's Cancer Group protocol 9942: a report from the Children's Oncology Group. Pediatr Blood Cancer 59:1183-1189, 2012

18. Gnekow AK, Walker DA, Kandels D, Picton S, Giorgio Perilongo, Grill J, et al: A European randomised controlled trial of the addition of etoposide to standard vincristine and carboplatin induction as part of an 18-month treatment programme for childhood ( $\leq 16$ years) low grade glioma - a final report. Eur J Cancer 81:206-225, 2017

19. Grasso CS, Tang Y, Truffaux N, Berlow NE, Liu L, Debily MA, et al: Functionally defined therapeutic targets in diffuse intrinsic pontine glioma. Nat Med 21:555-559, 2015

20. Grill J, Massimino M, Bouffet E, Azizi AA, McCowage G, Cañete A, et al: Phase II, open-label, randomized, multicenter trial (HERBY) of bevacizumab in pediatric patients with newly diagnosed high-grade glioma. J Clin Oncol 36:951958, 2018

21. Gururangan S, Fangusaro J, Poussaint TY, McLendon RE, Onar-Thomas A, Wu S, et al: Efficacy of bevacizumab plus irinotecan in children with recurrent low-grade gliomasa Pediatric Brain Tumor Consortium study. Neuro Oncol 16:310-317, 2014

22. Haas-Kogan DA, Banerjee A, Poussaint TY, Kocak M, Prados MD, Geyer JR, et al: Phase II trial of tipifarnib and radiation in children with newly diagnosed diffuse intrinsic pontine gliomas. Neuro Oncol 13:298-306, 2011

23. Hoffman LM, Geller J, Leach J, Boue D, Drissi R, Lu C, et al: A feasibility and randomized phase II study of vorinostat, bevacizumab, or temozolomide during radiation followed by maintenance chemotherapy in newly-diagnosed pediatric high-grade glioma: Children's Oncology Group study ACNS0822. Neuro Oncol 17 (Suppl 3):iii39-iii40, 2015 (Abstract TR-14)

24. Jakacki RI, Cohen KJ, Buxton A, Krailo MD, Burger PC, Rosenblum MK, et al: Phase 2 study of concurrent radiotherapy and temozolomide followed by temozolomide and lomustine in the treatment of children with high-grade glioma: a report of the Children's Oncology Group ACNS0423 study. Neuro Oncol 18:1442-1450, 2016

25. Jennings MT, Sposto R, Boyett JM, Vezina LG, Holmes E, Berger MS, et al: Preradiation chemotherapy in primary high-risk brainstem tumors: phase II study CCG-9941 of the Children's Cancer Group. J Clin Oncol 20:3431-3437, 2002
26. Jones DT, Kocialkowski S, Liu L, Pearson DM, Bäcklund LM, Ichimura K, et al: Tandem duplication producing a novel oncogenic BRAF fusion gene defines the majority of pilocytic astrocytomas. Cancer Res 68:8673-8677, 2008

27. Kieran MW, Chisholm J, Casanova M, Brandes AA, Aerts I, Bouffet E, et al: Phase I study of oral sonidegib (LDE225) in pediatric brain and solid tumors and a phase II study in children and adults with relapsed medulloblastoma. Neuro Oncol 19:1542-1552, 2017

28. Korshunov A, Ryzhova M, Hovestadt V, Bender S, Sturm D, Capper D, et al: Integrated analysis of pediatric glioblastoma reveals a subset of biologically favorable tumors with associated molecular prognostic markers. Acta Neuropathol 129:669-678, 2015

29. Krueger DA, Care MM, Agricola K, Tudor C, Mays M, Franz DN: Everolimus long-term safety and efficacy in subependymal giant cell astrocytoma. Neurology 80:574580,2013

30. Lafay-Cousin L, Bouffet E, Onar-Thomas A, Billups CA, Hawkins C, Eberhart C, et al: ACNS1221: a phase II study for the treatment of non-metastatic desmoplastic medulloblastoma in children less than 4 years of age: a report from the Children's Oncology Group. Proc Am Soc Clin Oncol 35:10505, 2017 (Abstract)

31. Lafay-Cousin L, Smith A, Chi SN, Wells E, Madden J, Margol A, et al: Clinical, pathological, and molecular characterization of infant medulloblastomas treated with sequential high-dose chemotherapy. Pediatr Blood Cancer 63:15271534,2016

32. Lam C, Bouffet E, Tabori U, Mabbott D, Taylor M, Bartels U: Rapamycin (sirolimus) in tuberous sclerosis associated pediatric central nervous system tumors. Pediatr Blood Cancer 54:476-479, 2010

33. Lassaletta A, Scheinemann K, Zelcer SM, Hukin J, Wilson BA, Jabado N, et al: Phase II weekly vinblastine for chemotherapy-naïve children with progressive low-grade glioma: a Canadian Pediatric Brain Tumor Consortium study. J Clin Oncol 34:3537-3543, 2016

34. Laughton SJ, Merchant TE, Sklar CA, Kun LE, Fouladi M, Broniscer A, et al: Endocrine outcomes for children with embryonal brain tumors after risk-adapted craniospinal and conformal primary-site irradiation and high-dose chemotherapy with stem-cell rescue on the SJMB-96 trial. J Clin Oncol 26:1112-1118, 2008

35. Louis DN, Perry A, Reifenberger G, von Deimling A, Figarella-Branger D, Cavenee WK, et al: The 2016 World Health Organization Classification of Tumors of the Central Nervous System: a summary. Acta Neuropathol 131:803-820, 2016

36. MacDonald TJ, Arenson EB, Ater J, Sposto R, Bevan HE, Bruner J, et al: Phase II study of high-dose chemotherapy before radiation in children with newly diagnosed high-grade astrocytoma: final analysis of Children's Cancer Group Study 9933. Cancer 104:2862-2871, 2005

37. Mackay A, Burford A, Carvalho D, Izquierdo E, Fazal-Salom $\mathrm{J}$, Taylor KR, et al: Integrated molecular meta-analysis of 1,000 pediatric high-grade and diffuse intrinsic pontine glioma. Cancer Cell 32:520-537.e5, e525, 2017

38. Merchant TE, Bendal AE, Sabin N, Burger PC, Wu S, Boyett JM: A phase II trial of conformal radiation therapy for pediatric patients with localized ependymoma, chemotherapy prior to second surgery for incompletely resected ependymoma and observation for completely resected, differentiated, supratentorial ependymoma. Int J Radiat Oncol Biol Phys 93 Suppl:S1, 2015

39. Merchant TE, Kun LE, Wu S, Xiong X, Sanford RA, Boop FA: Phase II trial of conformal radiation therapy for pediatric low-grade glioma. J Clin Oncol 27:3598-3604, 2009

40. Merchant TE, Li C, Xiong X, Kun LE, Boop FA, Sanford RA: Conformal radiotherapy after surgery for paediatric ep- 
endymoma: a prospective study. Lancet Oncol 10:258-266, 2009

41. Merchant TE, Rose SR, Bosley C, Wu S, Xiong X, Lustig RH: Growth hormone secretion after conformal radiation therapy in pediatric patients with localized brain tumors. J Clin Oncol 29:4776-4780, 2011

42. Mishra KK, Squire S, Lamborn K, Banerjee A, Gupta N, Wara WM, et al: Phase II TPDCV protocol for pediatric lowgrade hypothalamic/chiasmatic gliomas: 15-year update. J Neurooncol 100:121-127, 2010

43. Morfouace M, Shelat A, Jacus M, Freeman BB III, Turner D, Robinson S, et al: Pemetrexed and gemcitabine as combination therapy for the treatment of Group3 medulloblastoma. Cancer Cell 25:516-529, 2014

44. Ostrom QT, de Blank PM, Kruchko C, Petersen CM, Liao P, Finlay JL, et al: Alex's Lemonade Stand Foundation Infant and Childhood Primary Brain and Central Nervous System Tumors Diagnosed in the United States in 2007-2011. Neuro Oncol 16 (Suppl 10):x1-x36, 2015

45. Packer RJ, Gajjar A, Vezina G, Rorke-Adams L, Burger PC, Robertson PL, et al: Phase III study of craniospinal radiation therapy followed by adjuvant chemotherapy for newly diagnosed average-risk medulloblastoma. J Clin Oncol 24:42024208, 2006

46. Pajtler KW, Mack SC, Ramaswamy V, Smith CA, Witt H, Smith A, et al: The current consensus on the clinical management of intracranial ependymoma and its distinct molecular variants. Acta Neuropathol 133:5-12, 2017

47. Palmer SL, Armstrong C, Onar-Thomas A, Wu S, Wallace $\mathrm{D}$, Bonner MJ, et al: Processing speed, attention, and working memory after treatment for medulloblastoma: an international, prospective, and longitudinal study. J Clin Oncol 31:3494-3500, 2013

48. Pfister S, Janzarik WG, Remke M, Ernst A, Werft W, Becker $\mathrm{N}$, et al: BRAF gene duplication constitutes a mechanism of MAPK pathway activation in low-grade astrocytomas. J Clin Invest 118:1739-1749, 2008

49. Phoenix TN, Patmore DM, Boop S, Boulos N, Jacus MO, Patel YT, et al: Medulloblastoma genotype dictates blood brain barrier phenotype. Cancer Cell 29:508-522, 2016

50. Pollack IF: Brain tumors in children. N Engl J Med 331:1500-1507, 1994

51. Pollack IF, Boyett JM, Yates AJ, Burger PC, Gilles FH, Davis RL, et al: The influence of central review on outcome associations in childhood malignant gliomas: results from the CCG-945 experience. Neuro Oncol 5:197-207, 2003

52. Pollack IF, Hamilton RL, Sobol RW, Burnham J, Yates AJ, Holmes EJ, et al: O6-methylguanine-DNA methyltransferase expression strongly correlates with outcome in childhood malignant gliomas: results from the CCG-945 cohort. J Clin Oncol 24:3431-3437, 2006

53. Pollack IF, Hamilton RL, Sobol RW, Nikiforova MN, LyonsWeiler MA, LaFramboise WA, et al: IDH1 mutations are common in malignant gliomas arising in adolescents: a report from the Children's Oncology Group. Childs Nerv Syst 27:87-94, 2011

54. Pollack IF, Stewart CF, Kocak M, Poussaint TY, Broniscer A, Banerjee A, et al: A phase II study of gefitinib and irradiation in children with newly diagnosed brainstem gliomas: a report from the Pediatric Brain Tumor Consortium. Neuro Oncol 13:290-297, 2011

55. Ramaswamy V, Remke M, Bouffet E, Bailey S, Clifford SC, Doz F, et al: Risk stratification of childhood medulloblastoma in the molecular era: the current consensus. Acta Neuropathol 131:821-831, 2016

56. Robinson GW, Kaste SC, Chemaitilly W, Bowers DC, Laughton S, Smith A, et al: Irreversible growth plate fusions in children with medulloblastoma treated with a targeted hedgehog pathway inhibitor. Oncotarget 8:69295-69302, 2017
57. Robinson GW, Orr BA, Wu G, Gururangan S, Lin T, Qaddoumi I, et al: Vismodegib exerts targeted efficacy against recurrent sonic hedgehog-subgroup medulloblastoma: results from phase II pediatric brain tumor consortium studies PBTC-025B and PBTC-032. J Clin Oncol 33:2646-2654, 2015

58. Robinson GW, Rudneva VA, Buchhalter I, Billups CA, Waszak SM, Smith KS, et al: Risk-adapted therapy for young children with medulloblastoma (SJYC07): therapeutic and molecular outcomes from a multicentre, phase 2 trial. Lancet Oncol 19:768-784, 2018

59. Roujeau T, Machado G, Garnett MR, Miquel C, Puget S, Geoerger B, et al: Stereotactic biopsy of diffuse pontine lesions in children. J Neurosurg 107 (1 Suppl):1-4, 2007

60. Rutkowski S, Bode U, Deinlein F, Ottensmeier H, WarmuthMetz M, Soerensen N, et al: Treatment of early childhood medulloblastoma by postoperative chemotherapy alone. $\mathbf{N}$ Engl J Med 352:978-986, 2005

61. Schindler G, Capper D, Meyer J, Janzarik W, Omran H, Herold-Mende C, et al: Analysis of BRAF V600E mutation in 1,320 nervous system tumors reveals high mutation frequencies in pleomorphic xanthoastrocytoma, ganglioglioma and extra-cerebellar pilocytic astrocytoma. Acta Neuropathol 121:397-405, 2011

62. Schwartzentruber J, Korshunov A, Liu XY, Jones DT, Pfaff E, Jacob K, et al: Driver mutations in histone H3.3 and chromatin remodelling genes in paediatric glioblastoma. Nature 482:226-231, 2012

63. Shih DJ, Northcott PA, Remke M, Korshunov A, Ramaswamy V, Kool M, et al: Cytogenetic prognostication within medulloblastoma subgroups. J Clin Oncol 32:886-896, 2014

64. Souweidane MM, Kramer K, Pandit-Taskar N, Zhou Z, Haque S, Zanzonico P, et al: Convection-enhanced delivery for diffuse intrinsic pontine glioma: a single-centre, doseescalation, phase 1 trial. Lancet Oncol 19:1040-1050, 2018

65. Sposto R, Ertel IJ, Jenkin RD, Boesel CP, Venes JL, Ortega JA, et al: The effectiveness of chemotherapy for treatment of high grade astrocytoma in children: results of a randomized trial. A report from the Childrens Cancer Study Group. J Neurooncol 7:165-177, 1989

66. Stupp R, Mason WP, van den Bent MJ, Weller M, Fisher B, Taphoorn MJ, et al: Radiotherapy plus concomitant and adjuvant temozolomide for glioblastoma. N Engl J Med 352:987-996, 2005

67. Sturm D, Bender S, Jones DT, Lichter P, Grill J, Becher O, et al: Paediatric and adult glioblastoma: multiform (epi)genomic culprits emerge. Nat Rev Cancer 14:92-107, 2014

68. Tsang DS, Burghen E, Klimo P Jr, Boop FA, Ellison DW, Merchant TE: Outcomes after reirradiation for recurrent pediatric intracranial ependymoma. Int J Radiat Oncol Biol Phys 100:507-515, 2018

69. von Bueren AO, Kortmann RD, von Hoff K, Friedrich C, Mynarek M, Müller K, et al: Treatment of children and adolescents with metastatic medulloblastoma and prognostic relevance of clinical and biologic parameters. J Clin Oncol 34:4151-4160, 2016

70. von Bueren AO, von Hoff K, Pietsch T, Gerber NU, Warmuth-Metz M, Deinlein F, et al: Treatment of young children with localized medulloblastoma by chemotherapy alone: results of the prospective, multicenter trial HIT 2000 confirming the prognostic impact of histology. Neuro Oncol 13:669-679, 2011

71. Von Hoff DD, LoRusso PM, Rudin CM, Reddy JC, Yauch RL, Tibes R, et al: Inhibition of the hedgehog pathway in advanced basal-cell carcinoma. N Engl J Med 361:1164-1172, 2009

72. Walter AW, Mulhern RK, Gajjar A, Heideman RL, Reardon D, Sanford RA, et al: Survival and neurodevelopmental outcome of young children with medulloblastoma at St Jude 
Children's Research Hospital. J Clin Oncol 17:3720-3728, 1999

73. Wisoff JH, Sanford RA, Heier LA, Sposto R, Burger PC, Yates AJ, et al: Primary neurosurgery for pediatric low-grade gliomas: a prospective multi-institutional study from the Children's Oncology Group. Neurosurgery 68:1548-1555, 2011

74. Zarghooni M, Bartels U, Lee E, Buczkowicz P, Morrison A, Huang A, et al: Whole-genome profiling of pediatric diffuse intrinsic pontine gliomas highlights platelet-derived growth factor receptor $\alpha$ and poly (ADP-ribose) polymerase as potential therapeutic targets. J Clin Oncol 28:1337-1344, 2010

75. Zhukova N, Ramaswamy V, Remke M, Pfaff E, Shih DJ, Martin DC, et al: Subgroup-specific prognostic implications of TP53 mutation in medulloblastoma. J Clin Oncol 31:2927-2935, 2013

\section{Disclosures}

The authors report no conflict of interest concerning the materials or methods used in this study or the findings specified in this paper.

\section{Author Contributions}

Conception and design: all authors. Acquisition of data: all authors. Analysis and interpretation of data: all authors. Drafting the article: all authors. Critically revising the article: Pollack, Broniscer. Reviewed submitted version of manuscript: all authors. Approved the final version of the manuscript on behalf of all authors: Pollack. Study supervision: Pollack. Lead illustrator: Agnihotri.

\section{Correspondence}

Ian F. Pollack: Children's Hospital of Pittsburgh, Pittsburgh, PA. ian.pollack@chp.edu. 